\title{
DIFERENÇAS NO PERFIL DO ENOTURISTA QUE VISITA O DOURO: VELHO MUNDO VERSUS NOVO MUNDO
}

\author{
DIFFERENCES IN THE PROFILE OF THE ENOTOURISTS VISITING \\ THE DOURO: OLD WORLD VERSUS NEW WORLD \\ DIFERENCIAS EN EL PERFIL DEL ENOTURISTA QUE VISITA EL \\ DUERO: VIEJO MUNDO VERSUS NUEVO MUNDO
}

\author{
Adriano Costa (a.costa@ipg.pt)* \\ Ermelinda Oliveira (ermelindaol@ipg.pt) ${ }^{\star *}$ \\ Zaida Ferreira (zaidapinto@ipg.pt) ${ }^{\star \star \star}$
}

\section{RESUMO}

Quando falamos em "Velho Mundo" em termos de produção de vinhos, estamos a referir-nos aos países da Europa. Por "Novo Mundo", entendemos países cuja produção de vinhos se desenvolveu mais recentemente.

Assim, é perfeitamente natural que as pessoas oriundas de cada uma destas regiões tenham diferentes perfis e motivações, pelo que o presente estudo pretende identificar as principais motivações e traçar o perfil deste tipo de turista, de acordo com a região de origem.

É fundamental para um destino turístico compreender as diferentes motivações que levam os turistas a visitá-lo. O sucesso dos destinos depende da análise dessas motivações turísticas e, por isso, no presente estudo, adotamos um modelo baseado nas motivações push e pull. Partindo da revisão da literatura e da realização de entrevistas exploratórias, foi construído um questionário que foi aplicado na região do Douro. Da análise dos resultados, podemos concluir que existem diferenças estatisticamente significativas nos fatores Gastronomia (push), Oferta de Atividades Enoturísticas, Oferta de Atividades Culturais, Históricas e Serviços, Diversidade e Qualidade Gastronómica e Reputação da Região (pull).

Estes elementos/fatores terão certamente implicações importantes a diferentes níveis, como, o do marketing dos destinos, especialmente quanto à segmentação de mercados, elaboração de programas de 
promoção e tomadas de decisão sobre o destino turístico (a eleger).

Palavras-chave: Enoturismo, Motivações, Push e Pull, Velho Mundo e Novo Mundo, Douro.

\begin{abstract}
When we talk about the Old World in terms of wine production, we are referring to the European countries, whose wine production has developed recently.

Thus, it is quite natural that people from each of these regions have different profiles and motivations and, because of that, the present study intends to identify the main motivations and draw the profile of this type of tourist, according to the origin region.

It has become fundamental for a tourist destination to understand the different motivations that drive tourists to travel. The success of the destinations depends on a very detailed analysis of the different tourist motivations and, in this study, we adopted a model based on the push and pull motivations. Based on the literature review and exploratory interviews, a questionnaire was constructed and later applied in the region of Douro Tourism Complex. From the analysis of the results, we can conclude that there are statistically significant differences in the factors related to Gastronomy (push), Offer of Wine tourism Activities, Offer of Cultural, Historical Activities and Services, Diversity and Gastronomic Quality and Reputation of the Region (pull).

This may have important implications for the marketing of destinations, especially at the level of market segmentation, design of promotion programmes and decision making at the tourist destination level.
\end{abstract}

Key-words: Wine tourism, Motivations, Push and Pull, Old World and New World, Douro.

\title{
RESUMEN
}

Cuando hablamos en el Viejo Mundo en términos de producción de vinos, nos referimos a los países de Europa. Por Nuevo Mundo, estamos aludiendo a países cuya producción de vinos se ha desarrollado más recientemente.

Así, es perfectamente natural que las personas oriundas de cada una 
de estas regiones tengan diferentes perfiles y motivaciones, por lo que el presente estudio pretende identificar las principales motivaciones y trazar el perfil de este tipo de turista, de acuerdo con la región de origen. Es fundamental para un destino turístico comprender las diferentes motivaciones que llevan a los turistas a viajar. El éxito de los destinos depende del análisis de esas motivaciones turísticas y, por eso, en el presente estudio, adoptamos un modelo basado en las motivaciones push y pull. A partir de la revisión de la literatura y de la realización de entrevistas exploratorias, se construyó un cuestionario que fue aplicado en la región del Duero. Del análisis de los resultados, podemos concluir que existen diferencias estadísticamente significativas en los factores gastronomía (push), oferta de actividades enoturísticas, oferta de actividades culturales, históricas y servicios, diversidad y calidad gastronómica y reputación de la región (pull).

Esto puede tener implicaciones importantes en el marketing de los destinos, especialmente en la segmentación de mercados, la elaboración de programas de promoción y toma de decisiones en el destino turístico.

Palabras clave: Enoturismo, motivaciones, Push e Pull, Viejo Mundo y Nuevo Mundo, Douro.

\footnotetext{
* CiTUR - Centro de Investigação, Desenvolvimento e Inovação em Turismo

** CiTUR - Centro de Investigação, Desenvolvimento e Inovação em Turismo

*** CiTUR - Centro de Investigação, Desenvolvimento e Inovação em Turismo
} 


\section{INTRODUÇÃO}

O enoturismo é um importante produto turístico que permite divulgar as potencialidades de determinadas regiões vitivinícolas e o seu aproveitamento turístico quer em termos de serviços quer em termos de património (Costa, 2003).

Desta forma, o conceito de enoturismo engloba não só a visita às vinhas, quintas, caves e adegas, para a prova e compra de vinhos, mas também a participação em experiências únicas, como sejam as vindimas, as pisas, os cursos relacionados com a temática do vinho e da vinha, bem como as diferentes associações à gastronomia (Costa, 2014). Assim, torna-se necessário conhecer as diferentes motivações dos enoturistas, bem como, saber quais as que são mais valorizadas. Por isso, as motivações turísticas são geralmente encaradas como um domínio relevante na investigação em turismo, nomeadamente, como fator explicativo e crítico do comportamento dos turistas, sobretudo ao nível da escolha dos produtos/destinos turísticos. Este tipo de investigação tem, por isso, um significado essencialmente instrumental e prático para os gestores dos destinos turísticos e das empresas ligadas à indústria do vinho. Assim, o desafio que se coloca ao estudo das motivações, no contexto do turismo, é desenvolver uma ferramenta objetiva que permita aos referidos gestores compreenderem a razão pela qual os seus produtos ou serviços são adquiridos ou preteridos, ou seja, para que possam perceber as razões das escolhas dos viajantes, perante a diversidade de oferta posta à sua disposição (Neves, 2007). O conhecimento das diferentes motivações é fundamental para que se estabeleçam estratégias que irão permitir a uma determinada região se tornar num destino turístico (Castray e Francis, 2003; Mitchell e Hall, 2006). Neste sentido, o ponto de partida do presente estudo foi analisar a natureza das diferentes motivações dos enoturistas e determinar de que forma este constructo deveria ser conceptualizado e operacionalizado.

Muitos dos estudos apresentados procuram conceptualizar a motivação turística com base nos fatores sociais e psicológicos que motivam ou criam o desejo de viajar (Dann, 1977, Iso-Ahola, 1982; Kastenholz, 2002; Mclntosh, Goeldner e Ritchie, 1995; Neves, 2007; Pearce, 1982; Pearce e Lee, 2005; Pimlott, 1947; Plog, 1974;). Desta forma, verifica- 
se que o estudo desta temática se tem focado num conjunto de teorias base, designadamente no Modelo das Necessidades de Viagem, o qual engloba a Travel Career Lader (TCL) e a Travel Career Patterns (TCP), no Modelo Sociopsicológico das Motivações Turísticas, no Modelo do Psicocentrismo e Alocentrismo de Plog, na Teoria Funcional das Atitudes e na Teoria Push e Pull.

Este trabalho pretende identificar as principais motivações dos enoturistas oriundos do "Velho Mundo" e "Novo Mundo" (em termos de produção vinícola), e que poderão ter implicações de marketing importantes para a promoção do Pólo de Turismo do Douro.

Assim, numa primeira fase efetuamos uma revisão bibliográfica sobre o conceito de enoturismo e das motivações push e pull. De seguida foi apresentada a metodologia adotada. Procedeu-se à análise e discussão dos resultados. Por último, foram apresentadas as principais conclusões, bem como as principais limitações do estudo.

\section{REVISÃO DE LITERATURA}

O Enoturismo - turismo em espaço rural ligado ao vinho e à vinha - é uma área forte e de grande crescimento dentro do turismo ( $O$ ' Neill e Charters, 2000). Apesar de ser um setor relativamente jovem, é um setor que tem grandes hipóteses de crescimento e que permite, a médio e longo prazo, ter sustentabilidade e rentabilidade (Hall e Macionis, 1998). Como referiu Hall et al. (1997), o Enoturismo substitui o ecoturismo como "buzzword" nova e quente e, como um nicho de mercado novo e importante, de grande potencial de crescimento.

O interesse no estudo do Enoturismo é bem demonstrado pelas diferentes publicações em diferentes países. Assim, destacamos as seguintes investigações: África do Sul (Preston-Whyte, 2000; Bruwer, 2003; Demhardt, 2003); Austrália (Hall, Cambourne, Macionis, e Johnson, 1997; Charters e Ali-Knight, 2002; Sparks, 2007; Galloway, Mitchell, Getz, Crouch e Ong, 2008; Alonso e Liu, 2010); Canadá (Hackett , 1998; Telfer 2001; Williams e Kelly 2001; Williams e Dossa, 2003; Hashimoto e Telfer, 2003; Getz e Brown 2006); Chile (Sharples, 2002); Croácia (Muhi, Katic, Kovacevic e Stankovic, 2010); Espanha (MarzoNavarro e Pedraja-Iglesias, 2009); Estados Unidos (Peters, 1997; Getz, Dowling, Carlsen e Anderson, 1999; Skinner,2000; Wargenau e Che, 
2006); França (Frochot, 2000); Grécia (Kilipiris e Karamanidis, 2010); Hungria (Szivas, 1999); Israel (Cohen e Bem-Nun, 2009); Itália (Maizza e Rosato, 2008; Asero e Patti, 2009; Pikkemaat, Peters, Boksberger e Secco, 2009); Nova Zelândia (Hall, Cambourne, Macionis, e Johnson, 1997); Portugal (Costa 2003; Correia, 2005; Inácio, 2008;Brás, Costa e Buhalis, 2010; Costa Kastenholz, 2010; Costa, 2014; Brambilla, 2015); Reino Unido (Howley e Westering, 2008); Roménia (Ciopi, 2010).

De um modo geral todos os autores destacam o papel principal do vinho neste tipo de produto turístico. Além disso, todas as definições são unânimes em considerar o interesse das adegas, das vinhas e da própria região de vinhos como ponto central deste tipo de turismo.

Apesar do seu elevado pendor rural, o enoturismo pode ocorrer em espaço urbano, na medida em que algumas caves, adegas ou feiras, festas, festivais e eventos do vinho e da vinha não se situam ou ocorrem no campo, isolados, mas encontram-se estrategicamente posicionados em centros urbanos de média e grande dimensão (Inácio, 2008).

Independentemente de o enoturismo ter um carácter mais rural ou urbano, têm surgindo cada vez mais diferentes formas e escolhas enoturísticas, das quais podemos destacar: as rotas do vinho, as Aldeias Vinhateiras, as visitas guiadas às vinhas, quintas, caves, adegas, museus, centros de interpretação, a participação em atividades relacionadas com o vinho, como seja, vindimas, pisas, cursos, entre outras; festivais e eventos enoturísticos, cruzeiros ou passeios de helicóptero; criação de SPA's Vitivinícolas (termas de Alcafache, Hotel Aquapura no Douro). São formas cada vez mais diversificadas de desenvolvimento de uma vocação enoturística que se desenvolvem à medida que um destino turístico ou região vitivinícola se pretende afirmar enquanto local de enoturismo (Boniface (2003); Carlsen e Charters (2006); Getz,(2000); Getz e Brown (2006; Hall et al.(2003); Hjalager e Richards (2002); Inácio (2008)).

Contudo, um dos graves problemas que se coloca ao enoturismo, e em especial na Europa, é proveniente da dificuldade que as adegas, quintas, isto é, a indústria do vinho têm em conceber o turismo como um produto suscetível de se oferecer, e que pode gerar valor adicional não só com o aumento das suas vendas, margens, lucro, notoriedade, aproveitamento dos recursos (casa senhoriais, adegas, entre outras) mas também na diversificação dos produtos oferecidos e, consequen- 
temente, na diminuição dos riscos do negócio, posição esta partilhada em parte por Costa (2014).

O enoturismo pode assim contribuir para aumentar as exportações de vinho, educar os consumidores, fidelizar os visitantes para regressarem novamente e contribuir para uma boa imagem e publicidade dos vinhos e da região. Por isso, existe a necessidade de conhecer as principais motivações desta tipologia de turistas, de modo a criar produtos/serviços que vão de encontro às mesmas.

Partindo do princípio que as motivações são de duas grandes dimensões, nomeadamente, motivações push ou internas e motivações pull ou externas, torna-se agora importante traduzi-las num modelo de análise que oriente o desenvolvimento posterior da pesquisa. Este modelo tem em atenção a abordagem "push and pull", cujos pioneiros foram Crompton (1979) e Dann (1977).

Para o presente estudo, seguimos essencialmente a metodologia de autores como Baloglu e Uysal (1996), Crompton (1979), Correia et al. (2007), Cunha et al. (2005), Dann (1977), Fakeye e Crompton (1991), Jiao (2003), Sirikudta et al. (2010), Turnbull e Uysal (1995), Yoon e Uysal (2005) e Yuan e McDonald (1990), os quais defendem que existem dois tipos de motivações turísticas: as push e as pull. Assim, resultantes da revisão da literatura, as motivações push são aquelas que estão relacionadas com os desejos dos turistas e com os seus aspetos emocionais. As motivações pull são todas aquelas que estão relacionadas com os atributos de escolha de um determinado destino.

Saliente-se ainda que existem vários estudos que identificam o perfil dos consumidores de viagens de enoturismo, quer a nível europeu, também designado de "Velho Mundo", quer a nível dos novos países produtores de vinho, também, denominado de "Novo Mundo" (AFIT, 1999; Turismo de Portugal, 2006; Galloway et al., 2008). Os resultados não divergem muito quanto ao perfil, mas nada é indicado em relação às suas principais motivações, pelo que seria interessante saber se existem ou não diferenças significativas no que diz respeito às mesmas. Metodologia

Considerando que não existem estudos sobre as motivações dos enoturistas que visitam o Douro, procurou-se através de entrevistas a alguns responsáveis de algumas organizações no Douro, bem como da revisão bibliográfica de outros estudos sobre as motivações (Cunha 
et al., 2005; Galloway et al., 2008; Getz e Brown, 2006; Jiao, 2003; Mohammad e Som, 2010; Sirikudta et al., 2010; Yon e Uysal, 2005), devidamente adaptada a esta tipologia de turistas (enoturistas), obter um conjunto de itens relacionados com as motivações push e pull, os quais servirão de base para a elaboração do questionário final. Com base nestes pressupostos, construiu-se o modelo de análise que integra itens relacionados com motivações push e pull, também designadas de motivações internas e externas. Estas, foram analisadas, cada uma, através de 43 itens, tendo sido utilizada uma escala likert de 5 pontos, em que 1 correspondia a nada importante e 5, a muito importante (Yoon e Uysal, 2005). Foram também utlizadas questões para efeitos de caracterização socioeconómica, tipologia do enoturista (enquanto consumidor de vinhos) e perfil psicográfico.

No presente estudo, cuja componente empírica foi realizada em 2012, devido à impossibilidade de obter uma listagem de todos os elementos da população alvo, a opção incidiu sobre o processo de amostragem não aleatório. Contudo, procurámos que a amostra fosse o mais representativa possível dos enoturistas que visitam a região de Turismo do Douro. Assim, o processo seguido foi o método de amostragem por quotas, estratificado, onde se começou por dividir a amostra consoante o peso da proporção de cada mês no número de hóspedes na região de Turismo do Douro (I.N.E., 2012). Outra variável que foi considerada na estratificação foi a tipologia dos aderentes da Rota do Vinho do Porto e Douro, que o Turismo de Portugal agrupa em Quintas e Adegas, Alojamento, Restaurantes e Equipamentos de apoio (Neves, 2011).

Os questionários foram administrados com o apoio das unidades do Turismo do Douro pertencentes a cada uma das tipologias definidas pelo Turismo de Portugal: Quintas e Adegas, Unidades de Alojamento, Restaurantes e Equipamento de apoio, que se associaram com a investigação e com o autor do estudo, coadjuvado por alunos e ex-alunos da Escola Superior de Turismo e Hotelaria, do Instituto Politécnico da Guarda, os quais se encontravam a realizar estágios ou a trabalhar em algumas dessas unidades, entre os meses de Abril a Outubro.

Por outro lado, e de forma a catalogar a nossa amostra em Países do "Velho Mundo" e "Novo Mundo", seguimos o que é preconizado por Cruz (2013). Assim, o "Velho Mundo" é constituído pelos seguintes países: Itália, França, Espanha, Portugal, Áustria, Alemanha, Grécia, 
Hungria, Israel, Roménia, Eslováquia, Croácia, Chipre, Suíça, Inglaterra e Macedónia. No que concerne ao "Novo Mundo", fazem parte dele os seguintes países: E.U.A., Austrália, Nova Zelândia, Argentina, Chile, África do Sul, China, Índia, Uruguai, Brasil, México e Canadá.

Foram aplicados 600 questionários, dos quais apenas foram tratados 438.

Assim, para um nível de confiança de 95\% e de acordo com os valores inerentes ao caso em estudo, o nível de precisão da amostra é dado pela seguinte equação (Reis e Moreira, 1993):

○ivel de precisão obtido constitui um valor muito razoável, atendendo aos objetivos e aos constrangimentos temporais e financeiros da investigação. Só para se ter uma ideia, e segundo Hair et al.(2010), Pestana e Gageiro (2008), um nível de precisão de $\pm 5 \%$ é considerado adequado em investigações da área das Ciências Sociais, como é o caso desta.

\section{ANÁLISE DOS RESULTADOS}

A caracterização socioeconómica (nacionalidade, sexo, escalão etário, habilitações literárias, ocupação, rendimento e dimensão do agregado familiar) da amostra recolhida encontra-se no quadro seguinte:

\begin{tabular}{|c|c|c|c|}
\hline \multicolumn{2}{|c|}{ Variável } & $\mathbf{N}$ & $\%$ \\
\hline \multirow{3}{*}{ Nacionalidade } & Velho Mundo & $\mathbf{3 3 3}$ & $\mathbf{7 6 . 0}$ \\
\cline { 2 - 4 } & Novo Mundo & 105 & 24.0 \\
\cline { 2 - 4 } & Total & 438 & 100 \\
\hline \multirow{3}{*}{ Sexo } & Masculino & $\mathbf{2 9 1}$ & $\mathbf{6 6 . 4}$ \\
\cline { 2 - 4 } & Feminino & 147 & 33.6 \\
\cline { 2 - 4 } & Total & 438 & 100.0 \\
\hline \multirow{3}{*}{ Escalão etário } & 18 a 24 anos & 13 & 3.0 \\
\cline { 2 - 4 } & 25 a 34 anos & 65 & 14.8 \\
\cline { 2 - 4 } & 35 a 44 anos & 69 & 15.8 \\
\cline { 2 - 4 } & $\mathbf{4 5}$ a 54 anos & $\mathbf{1 2 6}$ & $\mathbf{2 8 . 8}$ \\
\cline { 2 - 4 } & 55 a 64 anos & 111 & 25.3 \\
\cline { 2 - 4 } & Mais de 65 anos & 438 & 12.3 \\
\cline { 2 - 4 } & Total & & \\
\cline { 2 - 4 } & & & 400.0 \\
\hline
\end{tabular}


Egitania

c i e $\Omega$ c i a

\begin{tabular}{|c|c|c|c|}
\hline \multicolumn{2}{|r|}{ Variável } & $\mathbf{N}$ & $\%$ \\
\hline \multirow{6}{*}{ Nível de ensino } & Ensino Básico & 8 & 1.9 \\
\hline & Ensino Secundário & 26 & 6.2 \\
\hline & Curso médio & 93 & 22.1 \\
\hline & Ensino Superior & 293 & 69.8 \\
\hline & $N / R$ & 18 & 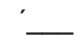 \\
\hline & Total & 438 & 100.0 \\
\hline \multirow{6}{*}{ Profissão } & Quadro médio e comerciantes & 86 & 19.7 \\
\hline & $\begin{array}{c}\text { Domésticos, desempregados, estudantes e outras } \\
\text { profissões }\end{array}$ & 59 & 13.5 \\
\hline & CEO/Profissionais Liberais e Quadros Superiores & 223 & 51.0 \\
\hline & Pensionistas/Reformados & 69 & 15.8 \\
\hline & $N / R$ & 1 & ‘-- \\
\hline & Total & 438 & 100.0 \\
\hline \multirow{6}{*}{$\begin{array}{l}\text { Dimensão do } \\
\text { agregado familiar }\end{array}$} & 1 pessoa & 19 & 4.4 \\
\hline & 2 pessoas & 172 & 39.9 \\
\hline & 3 pessoas & 126 & 29.2 \\
\hline & Igual ou superior a 4 pessoas & 114 & 26.5 \\
\hline & $N / R$ & 7 & ' \\
\hline & Total & 438 & 100.0 \\
\hline \multirow{6}{*}{$\begin{array}{l}\text { Rendimento men- } \\
\text { sal do agregado } \\
\text { familiar }\end{array}$} & Até $1000,00 €$ & 20 & 4.6 \\
\hline & De $1001,00 €$ a $2500,00 €$ & 101 & 23.5 \\
\hline & De $2501,00 €$ a $4000,00 €$ & 186 & 43.3 \\
\hline & Mais de $4000,00 €$ & 123 & 28.6 \\
\hline & $N / R$ & 8 & ‘ \\
\hline & Total & 438 & 100.0 \\
\hline
\end{tabular}

Quadro 1 - Caracterização socioeconómica da amostra

Fonte: Elaboração própria

Com base nesta informação, é possível traçar o perfil dos indivíduos inquiridos na amostra. Assim, cerca de três quatros dos indivíduos que pertencem aos países do chamado "Velho Mundo" são maioritariamente do sexo masculino, tendo idades iguais ou superiores a 45 anos (66.4\%), com um nível de escolaridade elevada, dado que cerca de 70\% têm um curso superior. No que concerne à dimensão do agregado familiar, este é em média de 2.89 pessoas, em que cerca de 40\% do referido agregado é constituído por duas pessoas. Relativamente ao 
rendimento do agregado familiar, este está compreendido na sua maioria entre $2501 €$ a $4000 €(43.3 \%)$.

De seguida, passaremos de uma forma resumida a fazer a respetiva caracterização deste tipo de turista, no que diz respeito à frequência de férias, período de antecipação da reserva, novidade em termos de destino, tipo de alojamento, duração da estadia, com quem está a passar férias, e gastos totais por dia e por pessoa na região (alojamento, alimentação, transporte, lembranças e outros), tendo em atenção a sua origem.

Da análise do quadro 2, podemos concluir que os enoturistas do Novo Mundo reservam com mais antecedência (5 semanas ou mais), e, também, 92.4\% dos mesmos é a primeira vez que val a esta região (Douro). A duração da sua visita é de 3.90 dias, sendo ligeiramente superior aos enoturistas do Velho Mundo. Os gastos totais, por dia e por pessoa, dos enoturistas do Novo Mundo (224.02€) são bem superiores aos do Velho Mundo (129.28€). Esta situação poderá estar relacionada com a proximidade dos países do Velho Mundo à região em causa. Em ambos os casos, os enoturistas viajam de um modo geral com o companheiro e têm como principais fontes de informação para selecionar um destino a Internet e a Recomendação de Outros.

\begin{tabular}{|c|l|c|c|c|c|}
\hline \multicolumn{2}{|c|}{$\begin{array}{c}\text { Variável } \\
\text { N }\end{array}$} & \multicolumn{2}{c|}{ Velho Mundo } & \multicolumn{2}{c|}{ Novo Mundo } \\
\cline { 3 - 7 } & $\%$ & $\mathbf{N}$ & $\%$ & \\
\hline \multirow{3}{*}{ No periodos de férias (ano) } & Nunca & 1 & 0.3 & 0 & 0 \\
\cline { 2 - 7 } & 1 Vez & 81 & 24.3 & 19 & 18.1 \\
\cline { 2 - 7 } & 2 Vezes & 157 & 47.1 & 49 & 46.7 \\
\cline { 2 - 7 } & 3 Vezes & 56 & 16.8 & 19 & 19.1 \\
\cline { 2 - 7 } & 4 ou mais & 38 & 11.4 & 18 & 17.1 \\
\cline { 2 - 7 } & Total & 333 & 100 & 105 & 100 \\
\hline
\end{tabular}


Egitania

s c i e $\Omega$ c i a

\begin{tabular}{|c|c|c|c|c|c|}
\hline \multirow{2}{*}{\multicolumn{2}{|c|}{$\begin{array}{c}\text { Variável } \\
\text { N }\end{array}$}} & \multicolumn{2}{|c|}{ Velho Mundo } & \multicolumn{2}{|c|}{ Novo Mundo } \\
\hline & & $\%$ & $\mathbf{N}$ & $\%$ & \\
\hline \multirow{7}{*}{$\begin{array}{c}\text { Antecedência na marcação } \\
\text { das férias }\end{array}$} & $\begin{array}{l}\text { Não re- } \\
\text { servei }\end{array}$ & 102 & 30.9 & 8 & 7.6 \\
\hline & $\begin{array}{l}\text { Há menos } \\
\text { de } 1 \text { se- } \\
\text { mana }\end{array}$ & 65 & 19.7 & 5 & 4.8 \\
\hline & $\begin{array}{l}\text { Há } 2 \text { ou } 3 \\
\text { semanas }\end{array}$ & 54 & 16.4 & 11 & 10.5 \\
\hline & $\begin{array}{l}\text { Há } 4 \text { ou } 5 \\
\text { semanas }\end{array}$ & 51 & 15.3 & 30 & 28.6 \\
\hline & $\begin{array}{l}\text { Há mais } \\
\text { de } 5 \text { se- } \\
\text { manas }\end{array}$ & 58 & 17.6 & 51 & 48.6 \\
\hline & $N / R$ & 3 & -- & 0 & --- \\
\hline & Total & 333 & 100 & 105 & 100 \\
\hline \multicolumn{2}{|l|}{$1^{\circ}$ Vez na região } & 170 & 51.2 & 97 & 92.4 \\
\hline \multirow[t]{2}{*}{ Tipo de Alojamento - } & Hotel & 145 & $44,1 \%$ & 51 & 49,6 \\
\hline & TER/TH & 109 & 33.1 & 34 & 32.4 \\
\hline \multicolumn{2}{|l|}{ Duração da estadia (dias) } & \multicolumn{2}{|c|}{3.61} & \multicolumn{2}{|c|}{3.90} \\
\hline \multicolumn{2}{|l|}{ Companhia da viagem } & \multicolumn{2}{|c|}{ Casal } & \multicolumn{2}{|c|}{ Casal } \\
\hline \multicolumn{2}{|c|}{ Gastos Totais (Por pessoa e por dia) } & \multicolumn{2}{|c|}{$129.28 €$} & \multicolumn{2}{|c|}{$224,02 €$} \\
\hline
\end{tabular}

Quadro 2 - Características psicográficas de enoturista (Velho Mundo versus Nova Mundo) Fonte: Elaboração própria

A tipologia de enoturista, enquanto consumidor de vinhos, influencia o que os mesmos compram e como realizam o seu consumo. Para isso, decidimos fazer esta análise de acordo com a sua nacionalidade, isto é, se são oriundos de países do "Velho Mundo" ou do "Novo Mundo".

\begin{tabular}{|c|c|c|c|c|c|c|c|c|}
\hline \multirow{2}{*}{ Item } & \multicolumn{4}{|c|}{ Velho Mundo } & \multicolumn{5}{c|}{ Novo Mundo } \\
\cline { 2 - 11 } & Média & Mediana & Moda & D.Padrão & Média & Mediana & Moda & D.Padrão \\
\hline Regularidade de Consumo & 5.66 & 6 & 7 & 2.295 & 6.35 & 7 & 7 & 1.946 \\
\hline Gasto mensal na compra de vinhos & 73 & 50 & 30 & 79.683 & 123.65 & 100 & 200 & 86.251 \\
\hline Compra média de garrafas de vinhos mês & 7.05 & 6 & 10 & 6.623 & 8.52 & 6 & 10 & 6.857 \\
\hline Compra média de garrafas de vinho da região & 1.81 & 1 & 0 & 3.077 & 1.34 & 0 & 0 & 3.651 \\
\hline Provas anteriores & 4.58 & 5 & 5 & 0.717 & 4.41 & 5 & 5 & 1.030 \\
\hline Recomendações de outros & 4.56 & 5 & 5 & 0.51 & 4.43 & 5 & 5 & 0.973 \\
\hline
\end{tabular}

Quadro 3 - Tipologia de enoturista (Velho Mundo versus Nova Mundo) Fonte: Elaboração própria 
Em termos descritivos, não existem diferenças significativas entre os enoturistas do Velho Mundo e Novo Mundo. No que concerne à regularidade de consumo, tendo esta sido analisada numa escala de 1 (nunca) a 9 (todos os dias), verificamos que os enoturistas do "Novo Mundo" apresentam um valor médio ligeiramente superior (6.65). Relativamente ao gasto mensal na compra de vinhos, os enoturistas do Novo Mundo (123.65€) apresentam valores muito superiores ao do Velho Mundo (73.00€). Este facto também é acompanhado do número de garrafas compradas. Mais ainda, podemos constatar que, em média, os enoturistas do Novo Mundo compram garrafas de vinho mais caras, cerca de 30\%, do que os provenientes do Velho Mundo.

Um dado importante a reter é que os indivíduos do Velho Mundo compram em média um número maior de garrafas de vinho da região (1.81). Este facto poderá estar relacionado com a proximidade da região e, consequentemente, com o conhecimento da mesma. Assim, também não é de estranhar que as principais fontes de informação utilizadas para comprar um vinho sejam as provas anteriores e a recomendações de outros. Por outro lado, e em relação à marca de vinho preferida da região, foi indicado pelos enoturistas oriundos do Novo Mundo o Porto (20/75). No caso dos enoturistas do Velho Mundo, foram indicadas duas marcas: Pintas (17) e Porto (15). É de salientar o elevado número de marcas referidas, bem como alguma confusão na identificação das mesmas, confundindo-se, por vezes, a marca de vinho com um determinado tipo de vinho da região, nomeadamente o vinho do Porto.

quadro seguinte contém as motivações push hierarquizadas pelo valor da sua média, tendo em atenção a origem dos enoturistas (Velho Mundo e Novo Mundo).

\begin{tabular}{|l|c|c|c|c|}
\hline \multirow{2}{*}{\multicolumn{1}{|c|}{ Itens }} & \multicolumn{2}{c|}{ Velho Mundo } & \multicolumn{2}{c|}{ Novo Mundo } \\
\cline { 2 - 5 } & Média & Ranking & Média & Ranking \\
\hline Conhecer diferentes culturas e estilos de vida & 4.566 & 1 & 4.600 & 1 \\
\hline Conhecer lugares diferentes & 4.553 & 1 & 4.610 & 1 \\
\hline Visitar lugares nunca antes visitados & 4.327 & 2 & 4.486 & 2 \\
\hline Procurar experiências únicas & 4.264 & 2 & 4.371 & 2 \\
\hline Descontrair física e mentalmente & 4.252 & 2 & 4.295 & 2 \\
\hline Procurar a novidade & 4.195 & 2 & 4.248 & 2 \\
\hline Saber mais sobre este lugar & 4.189 & 2 & 4.257 & 2 \\
\hline
\end{tabular}




\begin{tabular}{|c|c|c|c|c|}
\hline \multirow{2}{*}{ Itens } & \multicolumn{2}{|c|}{ Velho Mundo } & \multicolumn{2}{|c|}{ Novo Mundo } \\
\hline & Média & Ranking & Média & Ranking \\
\hline Provar novos sabores & 4.150 & 2 & 4.390 & 2 \\
\hline Fazer o que quero, sentir-me livre & 4.147 & 2 & 4.259 & 2 \\
\hline Provar novas comidas & 4.144 & 2 & 4.352 & 2 \\
\hline Desfrutar da paisagem natural & 4.120 & 2 & 4.219 & 2 \\
\hline Desfrutar de uma atmosfera calma & 4.115 & 2 & 4.133 & 2 \\
\hline brir horizontes & 4.024 & 2 & 4.229 & 2 \\
\hline Me divertir/entreter & 3.946 & 3 & 3.924 & 3 \\
\hline Apreciar a tranquilidade e serenidade do campo & 3.916 & 3 & 3.981 & 3 \\
\hline Escapar ao ambiente poluído & 3.598 & 3 & 3.448 & 4 \\
\hline Encontrar novas pessoas & 3.556 & 3 & 3.629 & 3 \\
\hline Satisfazer um desejo de fazer qualquer coisa diferente & 3.862 & 4 & 3.714 & 4 \\
\hline Fugir à rotina & 3.763 & 4 & 3.543 & 4 \\
\hline Fugir das exigências do trabalho diário & 3.706 & 4 & 3.429 & 5 \\
\hline Libertar-me da pressão do trabalho & 3.694 & 4 & 3.520 & 4 \\
\hline Visitar ambientes rurais & 3.486 & 4 & 3.648 & 3 \\
\hline Visitar amigos e familiares & 3.420 & 4 & 3.210 & 4 \\
\hline Vivenciar um modo de vida mais simples & 3.402 & 4 & 3.610 & 3 \\
\hline Reforçar os laços familiares & 3.324 & 4 & 3.200 & 4 \\
\hline Desenvolver amizades & 3.321 & 4 & 3.305 & 4 \\
\hline Visitar lugares de onde veio a minha família & 3.220 & 4 & 3.076 & 4 \\
\hline Observar os animais no seu habitat natural & 3.192 & 4 & 3.267 & 4 \\
\hline Cumprir compromissos familiares & 3.129 & 4 & 3.000 & 4 \\
\hline Procurar emoções fortes & 3.051 & 4 & 2.952 & 5 \\
\hline Falar com os meus amigos a respeito da viagem & 2.889 & 5 & 2.960 & 5 \\
\hline Partir à aventura & 2.880 & 5 & 2.999 & 5 \\
\hline Ser ousado e aventureiro & 2.766 & 5 & 2.829 & 5 \\
\hline Ir a lugares onde os meus amigos ainda não foram & 2.700 & 5 & 2.876 & 5 \\
\hline Visitar um destino que a maior parte das pessoas valoriza e/ou aprecia & 2.690 & 5 & 2.648 & 5 \\
\hline Desafiar as minhas capacidades & 2.687 & 5 & 2.648 & 5 \\
\hline Evitar a solidão & 2.675 & 5 & 2.752 & 5 \\
\hline Visitar um lugar da moda & 2.603 & 5 & 2.600 & 5 \\
\hline Visitar um lugar onde os meus amigos já foram & 2.477 & 6 & 2.543 & 5 \\
\hline Procurar experiências românticas & 2.324 & 6 & 2.505 & 5 \\
\hline Visitar um lugar frequentado por pessoas do meu estrato social & 2.322 & 6 & 2.371 & 6 \\
\hline Visitar um destino que irá impressionar os meus amigos e familiares & 2.210 & 6 & 2.219 & 6 \\
\hline Visitar locais frequentados por figuras públicas & 1.700 & 7 & 1.648 & 7 \\
\hline
\end{tabular}

Quadro 4 - Motivações Push (Velho Mundo versus Nova Mundo) Fonte: Elaboração própria 
os enoturistas do Velho Mundo, respetivamente com 4.566 e 4.553, quer para os enoturistas do Novo Mundo, com médias de 4.600 e 4.610. Em sentido oposto, o item que menor importância é atribuída para viajar é "Visitar lugares frequentados por figuras públicas", independentemente de serem enoturistas do Velho Mundo ou Novo Mundo, com uma média de 1.700 e 1.648, respetivamente.

quadro 5 apresenta os itens que serviram de base ao estudo das motivações pull hierarquizadas pelo valor da sua média e em função da origem dos enoturistas.

\begin{tabular}{|c|c|c|c|c|}
\hline \multirow{2}{*}{ Itens } & \multicolumn{2}{|c|}{ Velho Mundo } & \multicolumn{2}{|c|}{ Novo Mundo } \\
\hline & Média & Ranking & Média & Ranking \\
\hline $\begin{array}{l}\text { Restaurantes em espaços com características tradicio- } \\
\text { nais/regionais }\end{array}$ & 3.973 & 2 & 4.248 & 1 \\
\hline Grande qualidade da cozinha local & 4.027 & 1 & 4.124 & 1 \\
\hline Provas/degustações de vinhos & 3.714 & 2 & 4.103 & 1 \\
\hline $\begin{array}{l}\text { Grande número de adegas/caves para visitar na re- } \\
\text { gião }\end{array}$ & 3.919 & 2 & 4.095 & 1 \\
\hline Paisagem de grande beleza (cenários atrativos) & 3.991 & 2 & 4.086 & 1 \\
\hline Ampla gama e diversidade de restaurantes & 3.847 & 2 & 4.085 & 1 \\
\hline Visitas guiadas às caves/adegas & 3.877 & 2 & 4.076 & 1 \\
\hline Bons restaurantes Gourmet & 3.612 & 2 & 4.026 & 1 \\
\hline Região famosa de vinhos & 3.804 & 2 & 4.019 & 1 \\
\hline Ambiente não poluído & 3.931 & 2 & 3.980 & 2 \\
\hline Pessoal das adegas com conhecimentos sobre vinhos & 3.811 & 2 & 3.979 & 2 \\
\hline Rico património histórico e cultural & 4.045 & 1 & 3.971 & 2 \\
\hline Possibilidade de falar com os produtores de vinho & 3.747 & 2 & 3.923 & 2 \\
\hline Grande popularidade da região & 3.668 & 2 & 3.919 & 2 \\
\hline Possibilidade de interagir com enólogos & 3.579 & 2 & 3.919 & 2 \\
\hline Reputação da região & 3.714 & 2 & 3.886 & 2 \\
\hline Hospitalidade da população local & 3.892 & 2 & 3.876 & 2 \\
\hline Reputação das adegas & 3.642 & 2 & 3.743 & 2 \\
\hline Oferta de cursos sobre vinhos & 3.386 & 3 & 3.715 & 2 \\
\hline Oferta de atividades culturais e recreativas & 3.711 & 2 & 3.695 & 2 \\
\hline Grande qualidade dos serviços prestados & 3.794 & 2 & 3.655 & 2 \\
\hline $\begin{array}{l}\text { Alojamentos únicos, como pousadas ou turismo em es- } \\
\text { paço rural }\end{array}$ & 3.618 & 2 & 3.625 & 2 \\
\hline Segurança no destino & 3.455 & 3 & 3.595 & 2 \\
\hline Oferta de festivais de vinho & 3.476 & 3 & 3.582 & 2 \\
\hline
\end{tabular}




\begin{tabular}{|l|c|c|c|c|}
\hline \multirow{2}{*}{ Itens } & \multicolumn{2}{l|}{ Velho Mundo } & \multicolumn{2}{l|}{ Novo Mundo } \\
\cline { 2 - 5 } & Média & Ranking & Média & Ranking \\
\hline Oferta de festivais de gastronomia & 3.542 & 2 & 3.550 & 2 \\
\hline Boa sinalização para exploração do destino & 3.478 & 3 & 3.548 & 2 \\
\hline $\begin{array}{l}\text { Participar em atividades rurais (vindimas/pisas/ma- } \\
\text { tança do porco) }\end{array}$ & 3.330 & 3 & 3.504 & 2 \\
\hline Rotas de vinho bem sinalizadas & 3.446 & 3 & 3.481 & 3 \\
\hline Região calma e tranquila & 3.623 & 2 & 3.400 & 3 \\
\hline Facilidade na obtenção de informação turística & 3.477 & 3 & 3.381 & 3 \\
\hline Locais apropriados para a realização de piqueniques & 3.241 & 3 & 3.355 & 3 \\
\hline Clima agradável & 3.428 & 3 & 3.222 & 3 \\
\hline $\begin{array}{l}\text { Boas acessibilidades (aeroportuárias, rodoviárias, } \\
\text { ferroviárias, etc.) }\end{array}$ & 3.334 & 3 & 3.200 & 3 \\
\hline Bons trilhos pedestres & 3.235 & 3 & 3.197 & 3 \\
\hline Existência de centros de interpretação do vinho & 3.137 & 3 & 3.174 & 3 \\
\hline Possibilidade para adquirir novos vinhos e raros & 2.900 & 4 & 2.999 & 4 \\
\hline Boas infraestruturas de apoio (hospitais, bancos, etc.) & 3.144 & 3 & 2.954 & 4 \\
\hline Boa relação qualidade/preço & 3.445 & 3 & 2.905 & 4 \\
\hline Ampla gama de alojamento & 2.843 & 4 & 2.898 & 4 \\
\hline Grande diversidade de coisas para fazer & 2.664 & 4 & 2.410 & 5 \\
\hline Ampla gama de atracões & 2.566 & 4 & 2.381 & 5 \\
\hline Região com vida noturna animada & 2.355 & 5 & 2.029 & 5 \\
\hline Proximidade da minha residência & 2.244 & 5 & 1.705 & 6 \\
\hline
\end{tabular}

Quadro 5 - Motivações Pull (Velho Mundo versus Nova Mundo) Fonte: Elaboração própria

Da análise do quadro 5, podemos afirmar que, no caso das motivações pull, isto é, aquelas que estão relacionadas com a atratividade do destino, existem diferenças mais acentuadas entre os enoturistas oriundos do Velho Mundo e do Novo Mundo. Assim, e no que concerne aos enoturistas provenientes do Velho Mundo, estes dão maior importância aos itens "Rico património histórico e cultural" e "Grande qualidade da cozinha local", respetivamente com médias de 4.045 e 4.027. Em relação aos provenientes do Novo Mundo, os itens que mais valorizam são: "Restaurantes em espaços com características tradicionais/regionais" (4.248), "Grande qualidade da cozinha local" (4.124), "Provas/degustações de vinhos" (4.103), "Grande número de adegas/caves para visitar na região" (4.095), "Paisagem de grande beleza" (4.086), "Ampla gama e diversidade de restaurantes" (4.085), "Visitas guiadas às caves/ 
adegas" (4.076), "Bons restaurantes gourmet" (4.026) e "Região famosa de vinhos" (4.019). Em sentido oposto, existe alguma uniformidade em relação aos itens que são menos valorizados por este tipo de turista, nomeadamente a "Proximidade da minha residência" e "Região com vida noturna animada".

Para identificar as diferentes dimensões motivacionais, foi utilizada a análise fatorial exploratória, recorrendo ao método de componentes principais. Para uma melhor interpretação dos fatores, recorreu-se a uma rotação dos eixos varimax. No que diz respeito à retenção dos fatores, aplicámos o critério de Kaiser, ou seja, retivemos apenas os fatores cujos valores próprios fossem superiores a um (Hair et al., 2010). Por outro lado, e de acordo com o preceituado por Hair et al. (2010), apenas considerámos os itens cujo peso no fator fosse maior do que 0.5 e cuja comunalidade fosse superior a 0.5.

Deste modo, e no que concerne às motivações push, foram encontrados 7 fatores que esclarecem 75.06\% da variância explicada. A medida de KMO é de 0.831, superior ao valor mínimo propostos por Kaiser (1970;1974). 
Eggitania

$s$ c i e $n$ c i a

\begin{tabular}{|c|c|c|c|c|c|c|}
\hline Fatores Push & Peso & $\begin{array}{l}\text { Comu-nali- } \\
\text { dade }\end{array}$ & $\begin{array}{l}\text { Valor } \\
\text { Próprio }\end{array}$ & Variância & Média & $\begin{array}{l}\text { Desvio } \\
\text { Padrão }\end{array}$ \\
\hline Prestigio & & & 4.477 & 15.989 & 2.39 & 0.831 \\
\hline Visitar um lugar frequentado por pessoas do mev estrato social & 0.839 & 0.733 & & & & \\
\hline Visitar um lugar onde os meus amigos já foram & 0.746 & 0.630 & & & & \\
\hline $\begin{array}{l}\text { Visitar um destino que irá impressionar os meus amigos e fa- } \\
\text { miliares }\end{array}$ & 0.860 & 0.784 & & & & \\
\hline Visitar locais frequentados por figuras públicas & 0.741 & 0.646 & & & & \\
\hline $\begin{array}{l}\text { Visitar um destino que a maior parte das pessoas valoriza e/ } \\
\text { ou aprecia }\end{array}$ & 0.771 & 0.610 & & & & \\
\hline Visitar um lugar da moda & 0.783 & 0.739 & & & & \\
\hline Ir a lugares onde os meus amigos ainda não foram & 0.564 & 0.512 & & & & \\
\hline Reforço dos Laços Familiares & & & 3.759 & 13.426 & 3.13 & 1.054 \\
\hline Evitar a solidão & 0.522 & 0.575 & & & & \\
\hline Visitar lugares de onde veio a minha família & 0.851 & 0.777 & & & & \\
\hline Visitar amigos e familiares & 0.911 & 0.843 & & & & \\
\hline Reforçar os laços familiares & 0.926 & 0.882 & & & & \\
\hline Cumprir compromissos familiares & 0.844 & 0.786 & & & & \\
\hline Escape/Fuga à rotina & & & 3.309 & 11.817 & 3.71 & 1.118 \\
\hline Fugir das exigências do trabalho diário & 0.909 & 0.857 & & & & \\
\hline Fugir à rotina & 0.918 & 0.879 & & & & \\
\hline Satisfazer um desejo de fazer qualquer coisa diferente & 0.839 & 0.770 & & & & \\
\hline Libertar-me da pressão do trabalho & 0.872 & 0.805 & & & & \\
\hline Aventura & & & 3.124 & 11.158 & 2.68 & 1.015 \\
\hline Partir à aventura & 0.890 & 0.832 & & & & \\
\hline Ser ousado e aventureiro & 0.906 & 0.880 & & & & \\
\hline Desafiar as minhas capacidades & 0.851 & 0.794 & & & & \\
\hline Procurar experiências românticas & 0.689 & 0.565 & & & & \\
\hline Novidade e Conhecimento & & & 2.295 & 8.197 & 4.50 & 0.614 \\
\hline Conhecer lugares diferentes & 0.841 & 0.748 & & & & \\
\hline Conhecer diferentes culturas e estilos de vida & 0.874 & 0.792 & & & & \\
\hline Visitar lugares nunca antes visitados & 0.790 & 0.641 & & & & \\
\hline Reencontro com a natureza & & & 2.196 & 7.842 & 3.64 & 0.767 \\
\hline Visitar ambientes rurais & 0.818 & 0.702 & & & & \\
\hline Vivenciar um modo de vida mais simples & 0.799 & 0.723 & & & & \\
\hline Apreciar a tranquilidade e serenidade do campo & 0.807 & 0.657 & & & & \\
\hline Gastronomia & & & 1.857 & 6.633 & 4.20 & 0.794 \\
\hline Provar novos sabores & & 0.925 & & & & \\
\hline Provar novas comidas & & 0.932 & & & & \\
\hline Total de Variância Explicada & \multicolumn{6}{|c|}{75.061} \\
\hline Alfa de Cronbach & \multicolumn{6}{|c|}{0.823} \\
\hline KMO & \multicolumn{6}{|c|}{0.831} \\
\hline
\end{tabular}

Quadro 6- Análise fotorial exploratória das motivações push Fonte: Elaboração própria 
Deste modo, o fator "Prestígio" é o mais importante ao nível das motivações push, o qual explica 15.989\% do total da variância explicadas (valor próprio=4.477). O segundo mais importante é o "Reforço de laços familiares", com um total de 13.426\% do total da variância explicada. Deste modo, estes dois fatores refletem o desejo dos enoturistas em descobrir algo de novo e viajar para este tipo de destino. De seguida, vamos passar a analisar as motivações pull ou externas, tendo em conta a análise fatorial exploratória feita aos 43 itens.

Da análise fatorial exploratória, resultaram 8 fatores, que explicam 70.454\% da variância explicada. A medida do KMO é de 0.889, bem superior ao mínimo definido por Kaiser (1970;1974). Os itens "Oferta de festivais de vinho" e "Oferta de festivais de gastronomia", estão incluídos em dois fatores. Contudo optámos por incluí-los somente no fator em que o seu peso fatorial é superior.

\begin{tabular}{|l|l|c|l|l|l|l|}
\hline Fatores Pull & Peso & $\begin{array}{c}\text { Comu- } \\
\text { nalida- } \\
\text { de }\end{array}$ & $\begin{array}{c}\text { Valor } \\
\text { Próprio }\end{array}$ & $\begin{array}{c}\text { Va- } \\
\text { riância }\end{array}$ & $\begin{array}{c}\text { Mé- } \\
\text { dia }\end{array}$ & $\begin{array}{c}\text { Desvio } \\
\text { Pa- } \\
\text { drão }\end{array}$ \\
\hline Ofertas de atividades enoturísticas & & & 7.045 & 19.041 & 3.64 & 0.813 \\
\hline Oferta de cursos sobre vinhos & 0.773 & 0.740 & & & & \\
\hline Provas/degustações de vinhos & 0.846 & 0.745 & & & & \\
\hline Visitas guiadas às caves/adegas & 0.836 & 0.761 & & & & \\
\hline $\begin{array}{l}\text { Participar em atividades rurais (vindimas/pisas/matança } \\
\text { do porco) }\end{array}$ & 0.601 & 0.538 & & & & \\
\hline Existência de centros de interpretação do vinho & 0.663 & 0.583 & & & & \\
\hline Pessoal das adegas com conhecimentos sobre vinhos & 0.806 & 0.697 & & & & \\
\hline Possibilidade de interagir com enólogos & 0.786 & 0.775 & & & & \\
\hline Rotas de vinho bem sinalizadas & 0.593 & 0.516 & & & & \\
\hline Possibilidade de falar com os produtores de vinho & 0.797 & 0.725 & & & & \\
\hline Grande número de adegas/caves para visitar na região & 0.764 & 0.706 & & & & \\
\hline Oferta de atividades culturais, históricas e serviços & & & 3.232 & 8.735 & 3.69 & 0.608 \\
\hline Hospitalidade da população local & 0.612 & 0.606 & & & & \\
\hline Oferta de atividades culturais e recreativas & 0.657 & 0.620 & & & & \\
\hline Rico património histórico e cultural & 0.735 & 0.577 & & & & \\
\hline $\begin{array}{l}\text { Boas acessibilidades (aeroportuárias, rodoviárias, ferro- } \\
\text { viárias, etc.) }\end{array}$ & 0.631 & 0.569 & & & & \\
\hline Facilidade na obtenção de informação turistica & 0.659 & 0.625 & & & & \\
\hline
\end{tabular}


Egitania

$s$ c i e $\Omega$ c i a

\begin{tabular}{|c|c|c|c|c|c|c|}
\hline Fatores Pull & Peso & $\begin{array}{c}\text { Comu- } \\
\text { nalida- } \\
\text { de }\end{array}$ & $\begin{array}{l}\text { Valor } \\
\text { Próprio }\end{array}$ & $\begin{array}{l}\text { Va- } \\
\text { riância }\end{array}$ & $\begin{array}{l}\text { Mé- } \\
\text { dia }\end{array}$ & $\begin{array}{c}\text { Desvio } \\
\text { Pa- } \\
\text { drão }\end{array}$ \\
\hline Grande qualidade dos serviços prestados & 0.652 & 0.572 & & & & \\
\hline Diversidade e qualidade gastronómica & & & 3.153 & 8.520 & 3.93 & 0.857 \\
\hline Grande qualidade da cozinha local & 0.827 & 0.781 & & & & \\
\hline Bons restaurantes Gourmet & 0.721 & 0.765 & & & & \\
\hline Ampla gama e diversidade de restaurantes & 0.868 & 0.871 & & & & \\
\hline $\begin{array}{l}\text { Restaurantes em espaços com características tradicionais/ } \\
\text { regionais }\end{array}$ & 0.823 & 0.772 & & & & \\
\hline Reputação da região & & & 3.011 & 8.138 & 3.75 & 0.807 \\
\hline Reputação da região & 0.866 & 0.770 & & & & \\
\hline Reputação das adegas & 0.821 & 0.751 & & & & \\
\hline Região famosa de vinhos & 0.828 & 0.791 & & & & \\
\hline Grande popularidade da região & 0.760 & 0.671 & & & & \\
\hline Oferta de diversão e divertimento & & & 2.930 & 7.918 & 2.47 & 1.200 \\
\hline Região com vida noturna animada & 0.873 & 0.830 & & & & \\
\hline Grande diversidade de coisas para fazer & 0.888 & 0.889 & & & & \\
\hline Ampla gama de atracões & 0.883 & 0.860 & & & & \\
\hline Condições básicas do destino & & & 2.923 & 7.900 & 3.32 & 0.795 \\
\hline Segurança no destino & 0.651 & 0.550 & & & & \\
\hline Clima agradável & 0.785 & 0.724 & & & & \\
\hline Boa relação qualidade/preço & 0.682 & 0.684 & & & & \\
\hline Região calma e tranquila & 0.761 & 0.690 & & & & \\
\hline Ampla gama de alojamento & 0.531 & 0.594 & & & & \\
\hline Condições naturais do destino & & & 2.184 & 5.903 & 3.50 & 0.812 \\
\hline Bons trilhos pedestres & 0.790 & 0.744 & & & & \\
\hline Paisagem de grande beleza (cenários atrativos) & 0.704 & 0.659 & & & & \\
\hline Locais apropriados para a realização de piqueniques & 0.739 & 0.689 & & & & \\
\hline Festivais de gastronomia e vinhos & & & 1.591 & 4.299 & 2.18 & 0.889 \\
\hline Oferta de festivais de vinho & 0.611 & 0.820 & & & & \\
\hline Oferta de festivais de gastronomia & 0.610 & 0.808 & & & & \\
\hline Total de Variância Explicada & \multicolumn{6}{|c|}{70.454} \\
\hline Alfa de Cronbach & \multicolumn{6}{|c|}{0.899} \\
\hline KMO & \multicolumn{6}{|c|}{0.889} \\
\hline
\end{tabular}

Quadro 7 - Análise fatorial exploratória das motivações pull Fonte: Elaboração próprio 
A "Oferta de atividades enoturísticas" e a "Oferta de atividades culturais, históricas e serviços" são os fatores mais importantes no que concerne às motivações pull, explicando respetivamente 19.041\% e 8.735\% do total da variância explicada. Estes dois fatores demonstram a importância que o destino tem relativamente à quantidade de ofertas enoturísticas, culturais, históricas e de serviços que o mesmo oferece, possibilitando uma ampla escolha por parte dos interessados.

De seguida, procedeu-se à análise descritiva da importância que cada uma dos grupos (Velho Mundo e Novo Mundo) atribui aos fatores anteriormente encontrados (ver quadro 8). Por sua vez, os resultados dos testes $T$ evidenciam que os fatores "Gastronomia" (GAS), "Oferta de atividades enoturísticas" (OAE), "Oferta de atividades culturais, históricas e serviços", "Diversidade e qualidade gastronómica" (OAC) e "Reputação da região" (RR) têm diferenças médias estatisticamente significativas (sig $\leq 0.05$ ) de acordo com a sua origem. Relativamente ao fator "Oferta de atividades culturais, históricas e serviços", as pessoas provenientes do Velho Mundo atribuem-Ihe maior importância. Em relação a todos os restantes fatores, as pessoas provenientes do Novo Mundo atribuem uma maior importância.

\begin{tabular}{|c|c|c|c|}
\hline \multirow{2}{*}{\multicolumn{2}{|c|}{$\begin{array}{l}\text { Fatores } \\
\text { Velho Mundo }\end{array}$}} & \multicolumn{2}{|c|}{ Nacionalidade } \\
\hline & & \multicolumn{2}{|c|}{$\begin{array}{l}\text { Novo Mundo } \\
\mathrm{N}=105\end{array}$} \\
\hline \multirow{7}{*}{$\frac{5}{5}$} & Prestígio (PRE) & 2.386 & 2.415 \\
\hline & Reforço dos Laços Familiares (RLF) & 3.154 & 3.048 \\
\hline & Escape/Fuga à Rotina (EFR) & 3.756 & 3.551 \\
\hline & Aventura (AVT) & 2.664 & 2.745 \\
\hline & Novidade e Conhecimento (NC) & 4.482 & 4.565 \\
\hline & Reencontro com a Natureza (REN) & 3.602 & 3.746 \\
\hline & Gastronomia (GAS) & 4.147 & 4.371 \\
\hline
\end{tabular}




\begin{tabular}{|l|l|l|l|}
\hline \multicolumn{2}{|l|}{ Fatores } & \multicolumn{2}{l|}{ Nacionalidade } \\
\cline { 2 - 4 } & \multirow{2}{*}{ Velho Mundo } & Novo Mundo & \\
\multirow{4}{*}{$\mathrm{N}=333$} & $\mathrm{~N}=105$ & \\
\hline \multirow{5}{*}{$\mathbf{\Xi}$} & Oferta de Atividades Enoturísticas (OAE) & 3.594 & 3.797 \\
\cline { 2 - 4 } & Oferta de Atividades Culturais, Históricas e Serviços (OAC) & 3.709 & 3.629 \\
\cline { 2 - 4 } & Diversidade e Qualidade Gastronómica (DQG) & 3.864 & 4.121 \\
\cline { 2 - 4 } & Reputação da Região (RR) & 3.707 & 3.892 \\
\cline { 2 - 4 } & Oferta de Diversão e Divertimento (ODD) & 2.528 & 2.273 \\
\cline { 2 - 4 } & Condições Básicas do Destino (CBD) & 3.359 & 3.204 \\
\cline { 2 - 4 } & Condições Naturais do Destino (CND) & 3.489 & 3.546 \\
\cline { 2 - 4 } & Oferta de festivais de gastronomia e vinho & 2.194 & 2.147 \\
\hline
\end{tabular}

Quadro 8 - Média dos índices compósitos das motivações de acordo com a origem

Fonte: Elaboração própria

\section{DISCUSSÃO DOS RESULTADOS}

A análise descritiva dos dados da amostra permitiu fazer uma breve descrição socioeconómica da mesma, sendo caraterizada por ser maioritariamente do sexo masculino, com idades superiores a 45 anos (66,4\%), com um elevado nível de escolaridade, sendo que estes resultados são muito idênticos aos estudos da AFIT (1999), Turismo de Portugal (2006), Galloway et.al. (2008) e.Marzo-Navarro e Pedreja-Iglésias (2009).

No que concerne às características psicográficas dos enoturistas do Novo Mundo, verificamos que os mesmos reservam com mais antecedência, com maior tempo de permanência na região e com gastos por pessoa e por dia de quase o dobro dos enoturistas do Velho Mundo. Esta situação poderá estar relacionada com a distância que a maioria dos países do Novo Mundo se encontra da região. Para além disso, os enoturistas do Novo Mundo, na sua grande maioria, é a primeira vez que vêm à região. Esta situação pode estar relacionada com a juventude deste tipo de destino/produto turístico que é o enoturismo, o qual começa a dar os primeiros passos em Portugal e a ser descoberto pelos novos consumidores deste produto. Seria muito importante que os diferentes agentes se organizassem em termos da oferta, de forma a criar produtos estruturados e que vão de encontro às necessidades deste tipo de enoturistas, satisfazendo-os e levando-os à repetição do 
destino.

Salienta-se o facto dos enoturistas do Novo Mundo terem uma regularidade de consumo, gastos mensais com a compra de vinhos, superior aos enoturistas do Velho Mundo. Todavia, a compra de garrafas de vinho da região é menor. Esta situação pode estar relacionada com o meio de transporte que os mesmos utilizam, nomeadamente o avião, que condiciona o transporte de maior número de garrafas de vinho da região. Contudo, dado que os enoturistas do Novo Mundo têm um elevado potencial de compra de vinhos, os diferentes agentes da região devem estudar uma forma de lhe fazer chegar os vinhos a sua casa, nos diferentes países, sem agravar o custo do mesmo. Desta forma, estão a alargar o seu mercado, com novos consumidores, os quais podem tornar-se nos embaixadores dos seus vinhos nos seus países. Não nos devemos esquecer que as principais fontes de informação utilizadas para a comprar um vinho são as provas anteriores e as recomendações de outros.

Para além do que foi exposto, este estudo pretende oferecer uma tentativa de compreensão das diferentes motivações dos enoturistas, tendo por base as motivações push e pull. Por outro lado, e de um modo geral, o modelo conceptual utilizado é na generalidade confirmado. $\bigcirc$ estudo reconfirma que o comportamento de viajem dos enoturistas é guiado por fatores internos e externos. Por outras palavras, os enoturistas decidem ir para um determinado destino porque pretendem satisfazer determinados desejos internos, ao mesmo tempo que as decisões de escolha do destino se baseiam nos atributos do mesmo.

Tendo em conta os fatores push identificados, o estudo indica que os fatores "Prestígio" e "Reforço dos laços familiares" são os mais importantes para explicar as necessidades intrínsecas que levam o enoturista a viajar. Relativamente aos fatores pull, por outro lado, demonstram que o Pólo de Turismo do Douro tem potencialidades para aumentar a duração média da estadia dos enoturistas e, consequentemente, incrementar os seus gastos, promovendo também a repetição da visita, através de um "passa palavra" positivo e de o aumento de compra de produtos da região. De facto, a região deveria ser capaz de capitalizar a oferta de atividades enoturísticas, culturais, históricas, gastronómicas e a própria reputação da região, dado ter sido a primeira região demarcada do mundo (I.V.V., 2013) e, ainda, ter sido considerada pela UNESCO 
em 2001 como Património da Humanidade. A abundância e diversidade destes recursos turísticos na região são amplamente reconhecidos como muito importantes e ativos, essenciais no desenvolvimento da indústria do turismo.

Tendo também em atenção os resultados obtidos a nível inferencial das diferenças médias estatisticamente significativas para os fatores "Gastronomia", "Oferta de atividades enoturísticas", "Oferta de atividades culturais, históricas e serviços", "Diversidade e qualidade gastronómica" e "Reputação da região", de acordo com a região de origem (Velho Mundo e Novo Mundo), as pessoas do Novo Mundo dão maior importância a todos eles, com exceção do fator "Oferta de atividades culturais, históricas e serviços" o qual deveria ter tido maior atenção na altura da criação e promoção dos diferentes pacotes turísticos para cada um destes mercados. Por isso, as autoridades governamentais e os restantes operadores no destino devem ter em atenção a importância atribuída aos diferentes fatores identificados, dado que os mesmos podem ser agentes fundamentais para aumentar a satisfação com os serviços e produtos do destino e, assim, melhorar a lealdade ao destino e aos seus produtos.

\section{CONCLUSÃO}

Os resultados do estudo empírico põem em evidência que as motivações turísticas estão intimamente relacionadas com as vantagens competitivas do destino. Como o enoturismo é um importante setor na economia da região e do país, pode-se argumentar que os resultados obtidos no estudo têm implicações políticas significativas na gestão das atrações base da região em causa, Douro, mas também das restantes regiões vitivinícolas do nosso país.

O estudo tem algumas limitações, a primeira das quais decorre da representatividade da amostra. É certo que tentámos minimizar o efeito da não aleatoriedade, mas não o conseguimos eliminar.

Por outro lado, temos uma segunda limitação, nomeadamente o facto de termos recolhido os dados entre abril e outubro. Este facto poderá levar a um ligeiro enviesamento da amostra em relação a este tipo de turistas, pelo que, propomos que o estudo seja efetuado durante todo o 


\begin{abstract}
ano desde que haja recursos humanos e financeiros para o fazer.
Por último, em virtude da relativa novidade do assunto, propomos que se realizem outros estudos, nesta e em outras regiões vitivinícolas portuguesas, de modo a confirmar ou desconfirmar as dimensões encontradas.
\end{abstract}

\title{
BIBLIOGRAFIA
}

AFIT (1999) - Agência Francesa de Engenharia Turística, in Inácio (2008). O enoturismo em Portugal: Da cultura do vinho ao vinho como cultura. Tese de Doutoramento em Geografia Planeamento Regional e Urbano, Faculdade de Letras da Universidade de Lisboa, Lisboa.

Alonso, A. D. e Liv, Y. (2010). Wine tourism development in emerging Western Australian regions. International Journal of Contemporary Hospitality Management, Vol. 22, n², pp. 245-262.

Asero, V. e Patti, S. (2009). From wine production to wine tourism experience: the case of Italy. Wine Economics, November, pp. $1-17$.

Baloglu, S. e Uysal, M. (1996). Market segments of push and pull motivations: A canonical correlation approach. International Journal of Contemporary Hospitality Management, Vol. 8, n³, pp. 32-38.

Boniface, P. (2003). Tasting Tourism: Travelling for Food and Drink. Hampshire: Ashgate Publishing.

Brambilla, A. (2015). Cultura e Enoturismo: um estudo na Região Demarcada do Douro. Tese de Doutoramento, Universidade de Aveiro, Aveiro.

Brás, J., Costa, C. e Buhalis, D. (2010). Network analysis and wine routes: the case of Bairrada Wine Route. The Service Industries Journal, Vol. 30, N. 10, August 2010, pp. 1621-1641.

Bruwer, J. (2003). South African wine routes: some perspectives on the wine tourism industry's structural dimensions and wine tourism product. Tourism Management, Vol. 24, pp. 423-435.

Carlsen, J. e Charters, S. (2006). Global Wine Tourism. Oxon, United Kingdom. Castray, A. e Francis, H. (2003). Exploring the Role of Relationship Marketing in Wine Tourism. ANZMAC Conference Proceedings Adelaide, 1-3 de December, Australian, pp. $1134-1141$.

Ciopi, M. O. (2010). Marketing Plan for the Development of Historical, Cultural and Wine Tourism in Prahova. Economic Sciences, Vol. 62, n², pp. $116-123$.

Charters, S. e Ali-Knight, J. (2002). Who is the wine tourist? Tourism Management, Vol.23, pp. 31 1-319.

Cohen, E. e Ben-Nun, L. (2009). The important dimensions of wine tourism expe- 


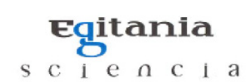

rience from potential visitors' perception. Tourism and Hospitality Research, Vol. 9, $n^{\circ} 1$, pp. 20-31.

Correia, A., Oom do Valle, P. e Moço, C. (2007). Why people travel to exotic places. International Journal of Culture, Vol.1, $n^{\circ} 1$, pp. 45-61.

Correia, Luís M. M. (2005). As rotas dos vinhos em Portugal - Estudo de caso da rota do vinho da Bairrada. Tese de Mestrado, Universidade de Aveiro, Aveiro. Costa, A. (2003). O Enoturismo em Portugal: o caso das rotas do vinho. $3^{a}$ Jornadas Ibéricas de Turismo, 3 e 4 de Maio, na Escola Superior de Educação de Coimbra; Coimbra.

Costa, A. (2014). Perfil e Motivações do Enoturista do Pólo de Turismo do Douro. Tese de Doutoramento, Universidade de Aveiro, Aveiro.

Costa, A. e Kastenholz, E. (2010). O Enoturismo na Rota do Vinho do Porto. $16^{\circ}$ Congresso da APDR, Universidade da Madeira, Funchal, 8 a 10 de Junho, Madeira, pp. 1714-1727.

Crompton, J. (1979). Motivations for pleasure vacation. Annals of Tourism Research, Vol 6; $n^{\circ} 4$; pp. 408-424.

Cruz, E. (2013). Vinhos do Velho Mundo e Novo Mundo. www.comtodovino.com. $\mathrm{br} / \mathrm{?}_{\mathrm{p}}=1759$, acedido a 1 de março de 2014.

Cunha, L., Antunes, M. H., Teixeira, P. A. e Pina, A. S. (2005). Motiv Tur. Centro de Investigações e Empresariais da Universidade Lusófona, Lisboa.

Dann, G. (1977). Anomie ego-enhancement and tourism. Annals of Tourism Research, vol.4, $n^{\circ} 4$, pp. 184-194.

Demhardt, I. (2003). Wine and tourism at the Fairest Cape: postapartheid trends in the Western Cape Province and Stellenbosch (South Africa). Journal of Travel and Tourism Marketing, Vol. 14, n³, pp. 113-130.

Fakeye, P. C. e Crompton, J. L. (1991). Image diferences between prospective first-time, and repeat visitors to the lower Rio Grande valley. Journal of Travel Research, Vol. 30, n², pp. 10-15.

Frochot, I. (2000). Wine tourism in France: a paradox? in Hall, M., Sharples, L., Cambourne, B. e Macionis, N. (2004). Wine Tourism Around the World. Oxford: Butterworth-Heinemann.

Galloway, G., Mitchell, R., Getz, D., Crouch, G. e Ong, B. (2008). Sensation seeking and the prediction of attitudes and behaviours of wine tourist. Tourism Management, Vol. 29, pp. 950-966.

Getz, D. (2000). Explore wine tourism: management, development, destinations. New York: Cognizant.

Getz, D. e Brown, G. (2006). Critical success factors for wine tourism regions: a demand analysis. Tourism Management, Vol. 27, pp. 146-158.

Getz, D., Dowling, R., Carlsen, J. e Anderson, D. (1999). Critical Success Factors for Wine Tourism. International Journal of Wine Marketing, Vol. 1 1, n³, pp. 
20-43.

Hackett, N. (1998). Vines, wines and visitors: A case study of agricultural diversification into winery tourism. Master thesis of Natural Resource Management, Simon Fraser University, Surrey.

Hair, J., Black, W., Babin, B. e Anderson, R. (2010). Multivariate data analysis: A global perspective. Upper Saddle River; NJ; Pearson.

Hall, C. M., Cambourne, B., Macionis, N. e Johnson, G. (1997). Wine tourism and network development in Australia and New Zealand: review, establishment and prospects. International Journal of Wine Marketing, Vol. 9, $n^{\circ} 2,3$, pp. 5-31. Hall, C. M. , Mitchell, R. e Sharples, L. (2003). Consuming places: the role of food, wine and tourism in regional development. In Hall, C. M., Sharples, L., Macionis, N. e Cambourne, B. (2003). Food Tourism around the World: Development, management, and markets. Butterworth-Heinemann, Linacre House, Jordan Hill, Oxford.

Hall, C. M. e Macionis, N. (1998). Wine tourism in Australia and New Zealand. In Butter, R. W., C. M. Hall e Jenkins, J. M.(1998). Tourism and Recreation in Rural Areas. John Wiley \& Sons, London, United Kingdom.

Hashimoto, A. e Telfer, D. (2003). Positioning an emerging wine route in the Niagara Region: Understanding the wine tourism market and implications for marketing. Journal of Travel and Tourism Marketing, Vol. 14, n³/4, pp. 61-76. Hialager, A. M. e Richards, G. (2002). Tourism and Gastronomy. Oxon: Routledge.

Hill, M. e Hill, A. (2008). Investigação por Questionário. Edições Sílabo, $2^{a}$ Edição, Lisboa.

Howley, M. e Westering, J. (2008). Developing wine tourism: A case study of the attitude of English wine producers to wine tourism. Journal of Vacation Marketing, Vol. 14, $n^{\circ} 1$, pp. 87-95.

Inácio, Ana Isabel (2008). O enoturismo em Portugal: Da cultura do vinho ao vinho como cultura. Tese de Doutoramento em Geografia Planeamento Regional e Urbano, Faculdade de Letras da Universidade de Lisboa, Lisboa.

I.N.E. (2012) - Instituto Nacional de Estatística. Dados Estatísticas das Dormidas e Hóspedes no Polo de Turismo do Douro. Instituto Nacional de Estatística, Lisboa. Iso-Ahola, S. E. (1982). Toward a Social Psychology of Theory of Tourism Motivation - A Rejoinder. Annals of Tourism Research, Vol.9, n², pp. 256-262.

I.V.V. (2013) - Instituto da Vinha e do Vinho. Regiões Vitivínicolas de Portugal. Jiao, F., (2003). A Motivational Analysis of Chinese Tourist to the United States: Push and Pull Motivations of Travel to Las Vegas. Master of Science Degree in Hotel Administration, University of Neveda, Las Vegas.

Kaiser, H. (1970). A Second Generation Little Jiffy. Psychometrika 35, 401 - 415. Kaiser, H. (1974). An index of factorial simplicity. Psychometrika 39, 31 -36.

Kastenholz, E. (2002). O papel da Imagem do Destino no Comportamento do 